\title{
Evaluation of initial fatigue growth behavior for surface-cracks
}

\author{
Ma Youli \\ College of Energy and Civil Engineering \\ Harbin University of Commerce \\ Harbin150028, China \\ my10505@aliyun.com
}

\author{
Li Rongjuan \\ College of Energy and Civil Engineering \\ Harbin University of Commerce \\ Harbin150028, China \\ lirongjuanlrj@gmail.com
}

\begin{abstract}
In order to predict the remaining life of the surface-cracks in the mechanical component, a method to evaluate the stress intensity factor of the crack tip is proposed. In this paper, finite element simulation is firstly used to evaluate stress intensity factor $K_{\mathrm{FEM}}$ of the crack under different load and sizes. The $K_{\mathrm{FEM}}$ is compared with $K$ calculated by Newman-Raju equation for the same crack. The evaluation results of $K_{\text {FEM }}$ are basically same with $K$ that calculated by the previous empirical formula, which verifies the reliability of the evaluation method. During the process of initial fatigue growth, stress intensity factor $K_{\text {est }}$ at the end of the surface-cracks is investigated by experiment. In results, the stress intensity factor proposed in this paper is efficacious for surface-cracks with residual stress, even though the load applied to surface-cracks and crack depth are unknown.
\end{abstract}

Keywords-surface-cracks; FEM analysis; stress intensity factor; fatigue growth; residual stress of pressure

\section{INTRODUCTION}

For engineering, such as oil pipe lines, ships and other structural components, surface-cracks will appear inevitably due to mechanical damage, corrosion and other surface defect during the process of manufacturing or using. Structural components with surface-cracks, resulting in rupture accidents often occurs, and it will causes catastrophic consequences [1, 2]. If the structure parts is large, it will allows the presents of local surface-cracks due to its larger size [3, 4]. However, in order to ensure that the structural failure does not occur within the design service period, the propagation rate of the crack and the breaking strength of the component must be predicted. In fracture mechanics, this prediction is achieved by evaluating the stress intensity factors at crack tip [5]. At present, researchers have done a lot of valuable research for the surface-cracks [6-8].

However, the above research works is done under the conditions that the load, the depth and the internal shape of the crack are known. During using, the surface-cracks in structure component is difficult to find.
The propagation characteristics of crack can be evaluated by stress intensity factor of the crack tip. For the initial through crack, the evaluation method of stress distribution and stress intensity factors around the crack tip is proposed by measuring opening displacement along the surface-cracks [9]. On the basis of this study, the calculation formula of the stress distribution along the surface-cracks and the method of evaluating the stress intensity factor are given. The evaluation method is evaluated by using finite element (FEM) in this paper. The reliability of the evaluation method is tested by comparison with the traditional Newman-Raju [10] calculation results. And using this method, the initial fatigue propagation characteristics of surface-cracks are studied experimentally.

\section{STRESS OF DISTRIBUTION AND STRESS INTENSITY FACTOR OF SURFACE-CRACKS}

In the center of the rectangular plate, there is a surfacecracks with length $2 a$ and depth $c$ which is shown in Fig. 1. At both ends of the plate (in the $y$ direction perpendicular to the crack), there is a uniform load $\sigma$, the amount of opening displacement $V\left(V=v^{+}-v^{-}\right)$at any position of the crack is measured as described in IV.B of this paper, the stress distribution $\sigma_{\text {est }}(x)$ along the surface crack can be expressed as in

$$
\sigma_{e s t}(x)=\frac{E}{4 \pi} \int_{-a}^{a} \frac{1}{t-x} \frac{d V}{d t} d t
$$

The stress intensity factor $K_{\text {est }}$ at the crack tip is calculated as shown in (2) [11]

$$
K_{e s t}=\frac{1}{\sqrt{\pi a}} \int_{-a}^{a} \sigma_{e s t}(x) \sqrt{\frac{a+x}{a-x}} d x
$$



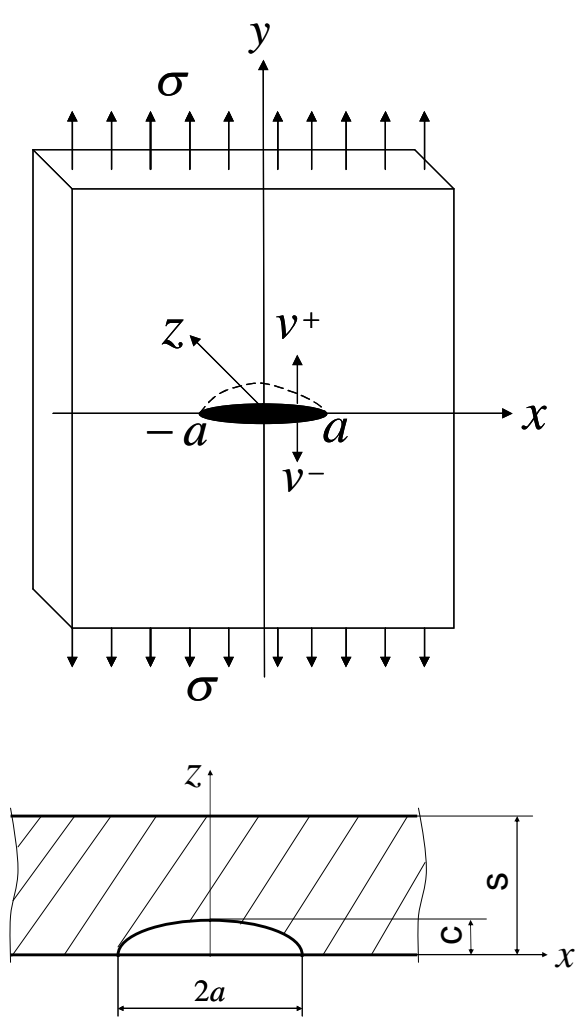

Fig. 1. Opening displacement of a surface-cracks in a finite plate.

\section{FEM Analytic Calculation}

\section{A. Analytical Conditions}

In order to test accuracy of the stress intensity factor proposed in this paper, FEM simulation is performed. The shape of the surface-cracks is oval, which is shown in Fig. 1. The size of the rectangular plate with cracks is same as that of the test piece used in the experiment in section IV. A, that is, width $W=50 \mathrm{~mm}$, length $H=180 \mathrm{~mm}$, and thickness $S=6$ $\mathrm{mm}$. The FEM modeling elements of the model segmentation is shown in Fig. 2, the model is a four-node element and the minimum factor of the crack tip is $1 \mu \mathrm{m}$. Compared with the experimental material, the elastic modulus of the material $E$ is 206.2 GPA, and the Poisson's ratio $v$ is 0.3 . The ratio of the depth to the length of the elliptical crack $c / a$ is $0.5,0.6,0.8$, respectively. The uniform load of $\sigma$ is $120 \mathrm{MPa}$ and is applied at both ends of the model in the direction perpendicular to the crack, then the analytical calculation is carried out.

\section{B. Analytical Results}

For the surface-cracks with unilateral crack length $a=3.0 \mathrm{~mm}$, the displacement of the opening under load is shown in Fig. 3. The abscissa in the figure is the distance from the center of the crack. The dashed line in the figure is an approximation calculation according to (3) [11].

$$
V(x)=\frac{A}{a} \sqrt{a^{2}-x^{2}}\left(B x^{4}+C x^{2}+D\right)
$$
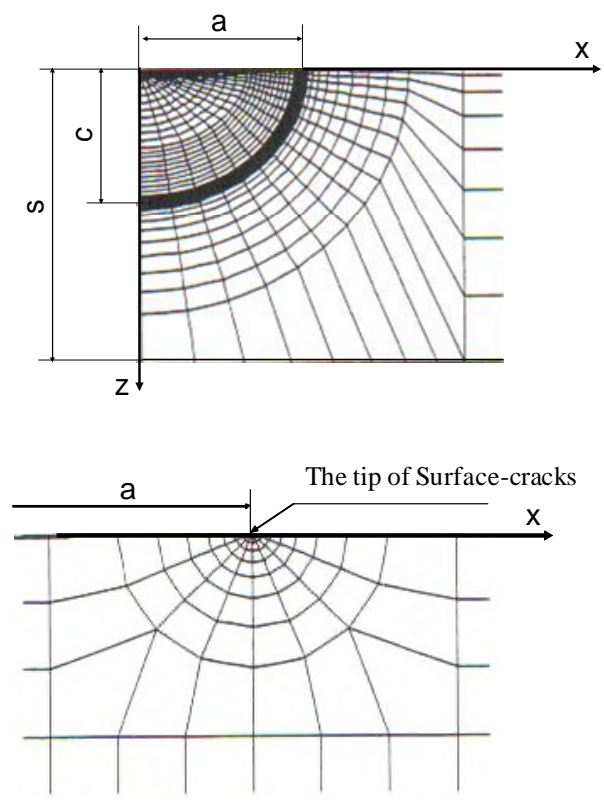

Fig. 2. Model of FEM analysis for surface-cracks.

In (3), A, B, C and D are coefficients. Under the same condition, the crack opening displacement decreases with the surface-cracks depth increasing, which indicates the effect of the crack depth on the opening displacement. The approximation analytic result $V(x)$ of the FEM is substituted into (1), and the stress distribution $\sigma_{\mathrm{FEM}}(x)$ along the crack is shown in Fig. 4.

In Fig. 4 , the stress distribution $\sigma_{\mathrm{FEM}}(x)$ along the crack is smaller than the load $\sigma$ applied to the model, and the value increases with surface-cracks depth increasing. From the simulation results, it is easier to know that the value of stress distribution $\sigma_{\mathrm{FEM}}(x)$ is affected by depth of surface-cracks. The calculation values of $\sigma_{\mathrm{FEM}}(x)$ are substituted into the formula (2), then the stress intensity factor $K_{\mathrm{FEM}}$ of the surface-cracks

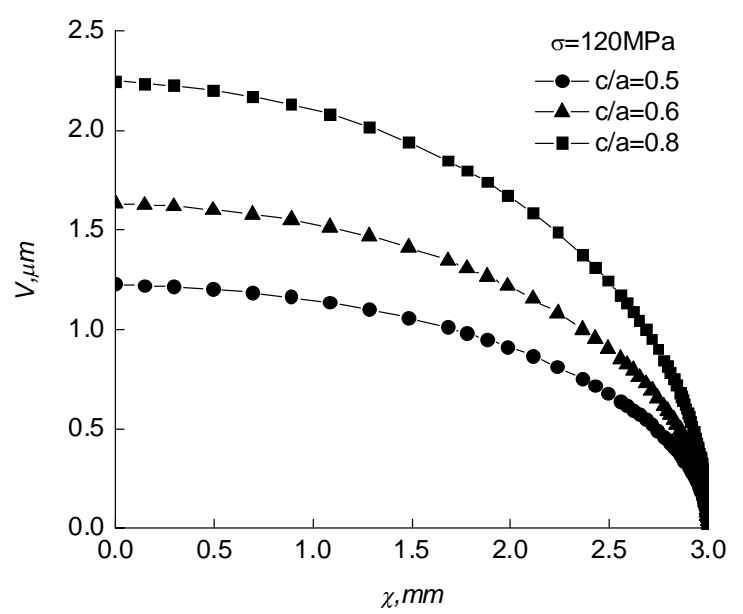

Fig. 3. Opening displacement distributions calculated from analysis for surface-cracks 


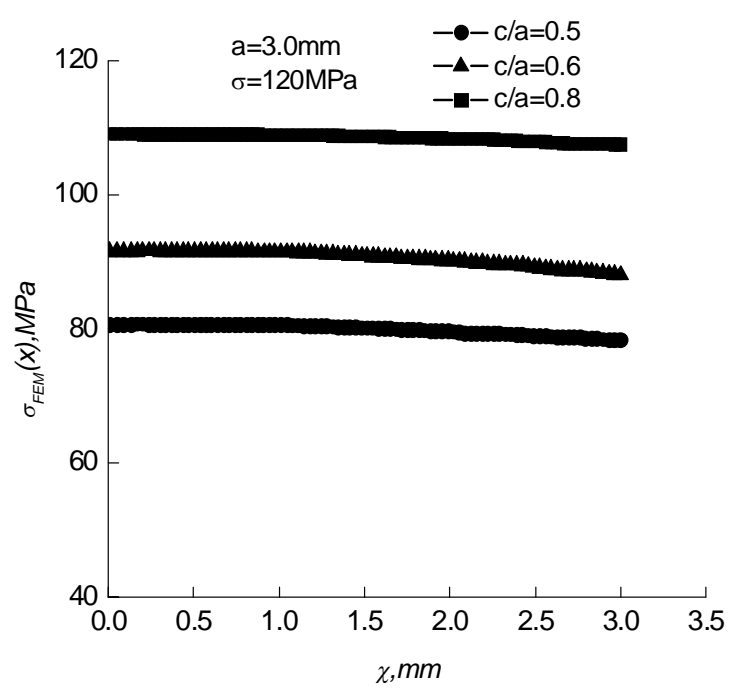

Fig. 4. Evaluated stress distributions along surface-cracks calculated from FEM analysis

at the end of the finite element is evaluated. In order to verify the reliability of the stress intensity factor evaluation method proposed in this paper, the traditional Newman-Raju formula (4) is used to calculate the stress intensity factor $K$ for the same surface-cracks. The results of $K_{\mathrm{FEM}}$ and $K$ are shown in Fig. 5.

$$
K=F \sigma \sqrt{\pi \frac{c}{Q}}
$$

Here, $\quad c$-Strength of one sided crack, m;

$\sigma$-Applied load, MPa;

$F, Q$-Coefficient.

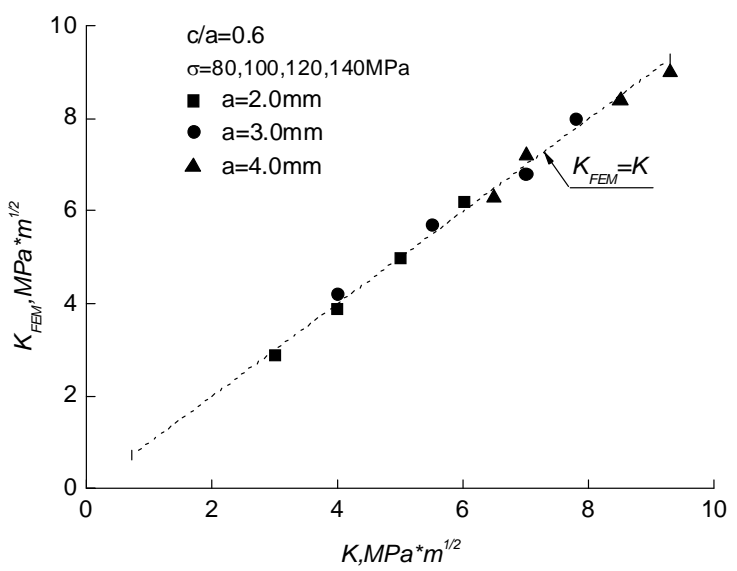

Fig. 5. Relationship between stress intensity factors $K_{\text {FEM }}$ and $K$.
From Fig. 5, it can be seen that the stress intensity factor $K_{\mathrm{FEM}}$ of the end of surface-cracks calculated by the evaluation method proposed in this paper, which is basically consistent with $K$ calculated by Newman-Raju formula. Therefore, even though the load and depth of surface-cracks are unknown, the stress intensity factor of the surface-cracks tip can be evaluated easily and accurately by the evaluation method proposed in this paper.

\section{SURFACE-CRACKS PROPAGATION EXPERIMENT}

\section{A. Surface-Cracks Speciment Production}

Experimental materials is 45 th steel and used widely in engineering. The mechanical properties are shown in Table 1.

\section{TABLE I. MECHANICAL PROPERTIES OF THE MATERIAL}

\begin{tabular}{|c|c|c|c|c|}
\hline $\begin{array}{c}\text { Poisson } \\
\text { ratio } \\
/ \mathbf{v}\end{array}$ & $\begin{array}{c}\text { Yield } \\
\text { strength } \\
/ \mathbf{M P a}\end{array}$ & $\begin{array}{c}\text { Tensile } \\
\text { strength } \\
/ \mathbf{M P a}\end{array}$ & $\begin{array}{c}\text { Elongation } \\
\text { rate } \\
/ \%\end{array}$ & $\begin{array}{c}\text { Section } \\
\text { shrinkage } \\
/ \%\end{array}$ \\
\hline 0.3 & 355 & 612 & 21.6 & 35.2 \\
\hline
\end{tabular}

The size of the rectangular specimen is shown in Fig. 6. In order to create a surface-cracks at a predetermined position, a non-penetrating center hole is formed in the center of the test piece, the diameter is $1.0 \mathrm{~mm}$ and depth is $1.0 \mathrm{~mm}$. After the specimen is processed, the surface of the specimen center is polished, so that it is easy to observe and measure during the experiment.

In Fig. 6, a specimen with a central hole was subjected to a cyclic load along the direction of its long axis using a fatigue tester, and a surface pre-crack required for the experiment was prepared at the center of the specimen surface. Fatigue experimental conditions are shown as follows: the fatigue test was carried out by a pulsed fatigue test machine with a sine wave load, frequency $20 \mathrm{~Hz}$, a stress ratio (ratio of minimum stress to maximum stress) $R=0$, maximum stress value $\sigma_{\max }$ $=120 \mathrm{MPa}$. Fatigue test is over until the unilateral crack length $a=2.02 \mathrm{~mm}$. In order to eliminate the residual stress around the crack, the fatigue treatment of the specimen after the end of the fatigue test keeps 1 hour with the heat treatment temperature $600{ }^{\circ} \mathrm{C}$.

Initial Fatigue Expansion Experiment of Surface-Cracks

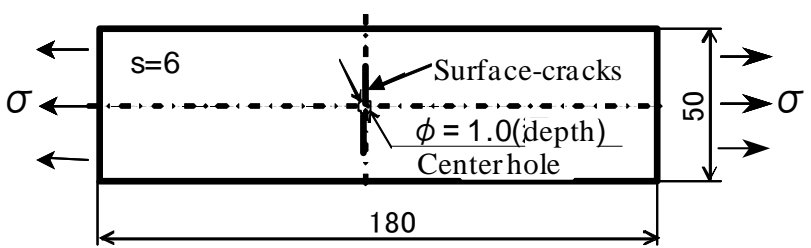

Fig. 6. Specimen with surface-cracks 
For the surface-cracks produced above, the initial fatigue expansion experiment was conducted on the fatigue test machine with sine wave of frequency $20 \mathrm{~Hz}$, stress ratio $\mathrm{R}=0$, and maximum stress value $\sigma_{\max }=120 \mathrm{MPa}$. When the crack is extended to the different length stage, the displacement of the opening along the crack is measured, and the fatigue propagation characteristics of the surface-cracks are investigated.

1) The displacement of the crack along the fatigue crack. The measurement of the amount of opening displacement along the crack is carried out by means of an optical miicroscope haveing a magnification of 100 times, and the measuredment method is illustrated in Fig. 7.

On the surface of the specimen, the small indentations with distance $50 \mu \mathrm{m}$ are printed in pairs and shows symmetrical distribution along the center of crack, each pair of microindentation with distance $\mathrm{y}_{0}=60 \mu \mathrm{m}$ are shown in Fig. 7 (a). The distance between each pair of indentation under load is shown in Fig. 7 (b). So the difference $V=y-y_{0}$ between load and unload is the amount of displacement in the crack opening direction at that point. The results of the distribution of the amount of open displacemnt along the full length of the crack are obtained by performing the above operations on each pair of indentations. The surface-cracks with single edge length $\mathrm{a}=4.08 \mathrm{~mm}$ after fatigue expansion, under the constant load of $\sigma=80,100$ and $120 \mathrm{MPa}$, the measurment results of along crack opening displacement are shown in Fig. 8. The dashed line in this figure is an approximation calculation according to (3).

2) Intensity factor in initial fatigue expansion of surfacecracks. When the unilateral length of the surface fatigue crack is $a=3.01$ and $4.96 \mathrm{~mm}$, the opening displacement is measured according to the same method for uniform load $\sigma=80,100$ and $120 \mathrm{MPa}$. Substituting the approximation value $V(x)$ of the

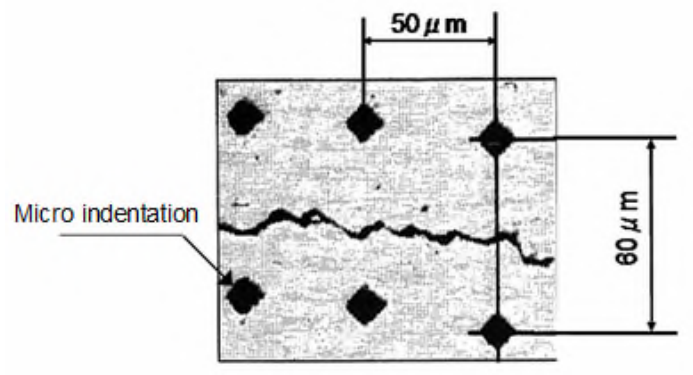

(a) Before loading

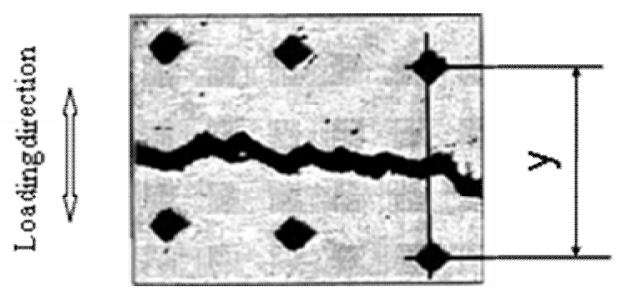

(b) After loading

Fig. 7. Measurement method of crack opening displacement distributions

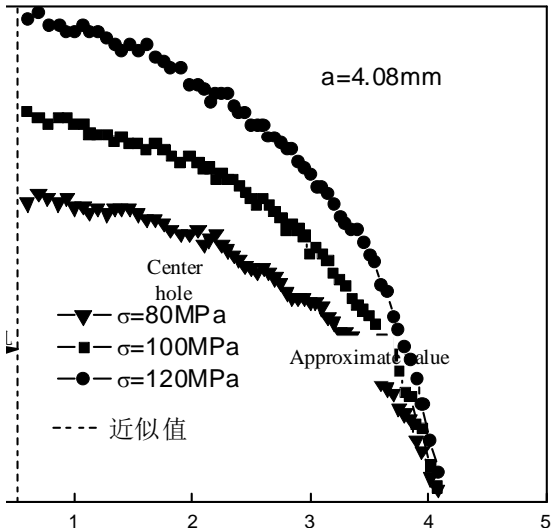

Fig. 8. Crack opening displacement distributions measured along surface fatigue crack

above mentioned opening displacement amount into (1), the stress distribution $\sigma(x)$ along the crack is calculated, and the (2) is used to evaluate the stress intensity factor $K_{\text {est }}$ at the end of the crack. At the same time, the stress intensity factor $K$ is calculated by the Newman-Raju formula (4) under the same conditions for the same crack. The relationship between $K_{\text {est }}$ and $K$ is shown in Fig. 9.

As can be seen from this figure, the $K_{\text {est }}$ is consistent with $K$ before the fatigue expansion of pre-crack (that is, the ". " in the figure). However, after the fatigue expansion of the crack, the stress strength factor $K_{\text {est }}$ obtained by the evaluation is much smaller than that of the traditional formula calculated. This can be considered as a result of the compression residual stress produced the fatigue expansion process.

Therefore, for the fatigue surface-cracks in the initial expansion stage found in the service oil pipeline, it is possible

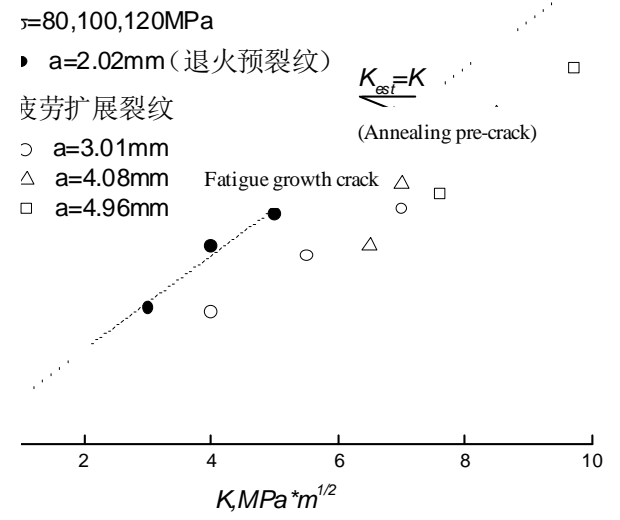

Fig. 9. Relationship between stress intensity factors $K_{\text {est }}$ and $K$ calculated from experimental surface-cracks 
to evaluate the stress intensity factor correctly by measuring an amount of open displacement along the crack even though load and surface-cracks depth are unknown. So that the safety evaluation the remaining life of pipeline can be achieved.

\section{CONCLUSION}

In this paper, we studies and discusses how to evaluate the initial expansion characteristics for surface-cracks (nonpenetrating surface defect) detected in the service oil pipeline. The main conclusions are shown as follows.

The stress distribution is calculated by measuring opening displacement along the surface-cracks which is proposed in this paper, and the stress intensity factor evaluation of the surface-cracks tip is carried out.

The surface-cracks is simulted by FEM, the stress intensity factor $\mathrm{K}_{\mathrm{FEM}}$ at the crack tip is evaluated. The value $\mathrm{K}_{\mathrm{FEM}}$ is consistent with the stress intensity factor $\mathrm{K}$ calculated by Newman-Raju formla for the same crack. Therefore, it is feasible to evaluate the stress intensity factor at the end of the surface-cracks using the method proposed in this paper, even though load and depth of crack are unknown.

In experiment, the stress intensity factor $\mathrm{K}_{\text {est }}$ at the end of surface-cracks in the initial expansion stage is evaluated. The value of $\mathrm{K}_{\text {est }}$ in the crack propagation process is lower than the value $\mathrm{K}$ calculated by Newman-Raju formula, which reflects the impact of the compressive residual stress around surfacecracks on the $\mathrm{K}_{\mathrm{est}}$ during fatigue growth.

Therefore, for surface-cracks at the initial expansion stage in oil pipeline, even if the force and depth of surface-cracks are unknown, the stress intensity factor of the crack tip can be evaluated by the evaluation method proposed in this paper.

\section{REFERENCES}

[1] Y. Jiang, X.L. Zhao, X.S. Chen, Y.H. Li, "Leakage analysis of elbow in slurry oil pipelines", J. Pipeline Tech. Equip. vol. 20(2), pp. 4, 2013.

[2] Y. Wang, Z. Xiao, "Safety evaluation standards for in-service oil and gas pipelines with defects", J. Oil \& Gas Storage Transport. vol. 32(6), pp. 587, 2013.

[3] J. Zhou, Y. Jiang, "Protection process about the accident causing from mechanic defect in oil-gas pipe-line," J. Oil \& Gas Storage Transport. vol. 31(2), pp. 86, 2012.

[4] X. Jiang, Y. Li, F. Du, "The research progress of corrosion and protection on pipe-line under the sea", J. Mater. Protect. vol. 43(4), pp. 24, 2010

[5] P. Li, "Failure accidents and typical cases for oil-gas pipelines", J. Weld. Pipelines, vol. 28(4), pp. 76, 2005.

[6] X. Gu, Z. Wu, "New empirical stress-intensity factor equations for surface cracks," J. Eng. Mech. vol. 25(7), pp. 35, 2008.

[7] G. Li, L. Hao, J. Li, "An expression of stress intensity factor in sucker rod string with surface crack", J. Oil Field Equip. vol. 36(12), pp. 14, 2007.

[8] H. Shu, "Calculating stress intensity factor for surface-cracks in thin pipelines", J. Oil \& Gas Storage Transport. vol. 20 (3), pp. 25, 2001.

[9] Y.L. Ma, "Initial fracture behavior and influencing factors of fatigue cracks in an oil-gas pipeline", J. Harbin Eng. Univ. vol. 33(8), pp. 984, 2012.

[10] J.C. Newman, I.S. Raju, "An empirical stress-intensity factor equation for the surface crack”, J. Eng. Fract. Mech. vol. 15(1), pp. 185, 1981.
[11] Y. L. Ma, "Study on fatigue crack propagation behavior under mixedmode conditions with compressive residual stress," Tokyo: Parliament Library, 2006 